\title{
Molecular Characterization of Chinese Hamster Cells Mutants Affected in Adenosine Kinase and Showing Novel Genetic and Biochemical Characteristics
}

\author{
Xianying A Cui, Tanvi Agarwal, Bhag Singh and Radhey S Gupta*
}

\begin{abstract}
Background: Two isoforms of the enzyme adenosine kinase (AdK), which differ at their N-terminal ends, are found in mammalian cells. However, there is no information available regarding the unique functional aspects or regulation of these isoforms.

Results: We show that the two AdK isoforms differ only in their first exons and the promoter regions; hence they arise via differential splicing of their first exons with the other exons common to both isoforms. The expression of these isoforms also varied greatly in different rat tissues and cell lines with some tissues expressing both isoforms and others expressing only one of the isoforms. To gain insights into cellular functions of these isoforms, mutants resistant to toxic adenosine analogs formycin $\mathrm{A}$ and tubercidin were selected from Chinese hamster $(\mathrm{CH})$ cell lines expressing either one or both isoforms. The AdK activity in most of these mutants was reduced to $<5 \%$ of wildtype cells and they also showed large differences in the expression of the two isoforms. Thus, the genetic alterations in these mutants likely affected both regulatory and structural regions of AdK. We have characterized the molecular alterations in a number of these mutants. One of these mutants lacking AdK activity was affected in the conserved NxxE motif thereby providing evidence that this motif involved in the binding of $\mathrm{Mg}^{2+}$ and phosphate ions is essential for AdK function. Another mutant, Fom ${ }^{R}-4$, exhibiting increased resistance to only Cadenosine analogs and whose resistance was expressed dominantly in cell-hybrids contained a single mutation leading to $\operatorname{Ser}_{191}$ Phe alteration in AdK. We demonstrate that this mutation in AdK is sufficient to confer the novel genetic and biochemical characteristics of this mutant. The unusual genetic and biochemical characteristics of the Fom $^{\mathrm{R}}-4$ mutant suggest that AdK in this mutant might be complexed with the enzyme AMP-kinase. Several other AdK mutants were altered in surface residues that likely affect its binding to the adenosine analogs and its interaction with other cellular proteins.
\end{abstract}

Conclusions: These AdK mutants provide important insights as well as novel tools for understanding the cellular functions of the two isoforms and their regulation in mammalian cells.

\section{Background}

Adenosine kinase (AdK) is a major purine salvage pathway enzyme belonging to the ribokinase family of proteins [1-4]. It plays a central role in regulating the intracellular and interstitial concentrations of the purine nucleoside adenosine (Ado), which exhibits potent

\footnotetext{
* Correspondence: gupta@mcmaster.ca

Department of Biochemistry and Biomedical Sciences, McMaster University,
} Hamilton, L8N 3Z5, Canada cardioprotective and neuroprotective activity [5-7]. During ischemia, the compromised regeneration of ATP causes an increase in the intracellular concentration of Ado, which results in its net efflux into extracellular space where it binds to $G_{i / o}$-coupled Ado receptors: $A_{1}$, $A_{2 A}, A_{2 B}$, and $A_{3}$, to modulates a variety of physiological responses to reduce tissue damage from ischemic injury [5,6,8-10]. The expression of AdK undergoes rapid coordinated changes in the brain following epileptic seizures or stroke, resulting in an acute surge of Ado, which 
serves to minimize damage to the brain $[6,11]$. Strong evidence in support of the protective role of Ado has been obtained from studies where transient down regulation of AdK after acute brain injury protected brain from seizures and cell death, whereas its overexpression as in epilepsy caused seizure aggravation and promoted cell death [11-13].

AdK, in addition to its central role in purine salvage and ATP catabolism, also plays a critical role in the maintenance of methylation reactions. In the S-adenosylmethionine (SAM) dependent methylation pathway, Ado and homocysteine (Hcy) are produced as a result of hydrolysis of S-adenosyl-homocysteine (SAH), which is the common end product of all methylation reactions [1,14-17]. The hydrolysis reaction, which is catalyzed by the enzyme SAH-hydrolase, is reversible and the equilibrium constant of this reaction favors SAH formation. Hence, unless the hydrolysis product, Ado and Hcy are rapidly removed, it will lead to the buildup of $\mathrm{SAH}$, which is a potent inhibitor of transmethylation reactions $[14,17,18]$. In the guinea-pig heart, the transmethylation pathway has been shown to be an important intracellular source of Ado under normal conditions and the Ado produced by this mechanism is mainly salvaged by AdK [19]. Studies with the AdK knockout mouse, which causes liver failure and early postnatal death [16], indicate that the effects of AdK deficiency on transmethylation reactions are the main underlying causes for its lethal effect [16]. The deficiency of AdK due to its pivotal role in the maintenance of transmethylation reaction also causes developmental abnormalities and reduced salt stress in plants [20,21].

Two isoforms of AdK are present in mammalian species [22-25]. These isoforms differ from each other only in their N-termini. The long isoform (AdK-L) of AdK contains an extra 20-21 amino acids in place of the first four amino acids of the AdK-short (AdK-S) isoform $[23,26]$. Studies with the recombinant AdK-L and AdK$S$ proteins have revealed no differences in their biochemical or kinetic properties [23](unpublished results). However, we recently showed that the $\mathrm{N}$-terminal extension in the AdK-L functions as a nuclear localization signal [27]. Thus, of the two AdK isoforms, AdK-L is targeted to the nucleus whereas AdK-S is localized in the cytoplasm [27]. The differential subcellular localization of these two AdK isoforms suggests that they carry out different physiological functions. However, there is no information available at present regarding the unique cellular functions of these isoforms or how their expression is regulated.

Unlike the lethal phenotype of $\mathrm{AdK}^{-1-}$ mice, AdK deficient mutants can be readily obtained in cultured cells by selecting in the presence of toxic concentrations of the Ado analogs [25,28-31]. Most of such mutants lack
AdK activity and some mutants that have been studied in detail contained large deletions within the AdK gene $[24,32]$. Our recent work shows that in contrast to the Chinese Hamster Ovary (CHO) cells that expresses only the AdK-L isoform, in the $\mathrm{CH}$ V79 cell line established from embryonic lung [33] both AdK-L and AdK-S isoforms are expressed. Hence, to gain further insights into the cellular functions of AdK, in the present work we report the isolation and characterization of mutants resistant to Ado analogs from V79 and other $\mathrm{CH}$ cell lines. Our results show that these mutants exhibit interesting differences in their cross-resistance pattern towards the $\mathrm{N}$ - and $\mathrm{C}$ - Ado analogs and also in the expression profiles of the two AdK isoforms. (Note: In $\mathrm{N}$-nucleosides the purine base is linked to ribose via a $\mathrm{N}-\mathrm{C}$ bond, whereas in $\mathrm{C}$-nucleosides this linkage involves a $\mathrm{C}-\mathrm{C}$ bond $[34,35])$. Several of these mutants contained novel molecular alterations in AdK affecting its activity/function. One of these mutants that exhibited increased resistance to only C-Ado analogs, and whose drug-resistance phenotype was dominantly expressed in cell hybrids formed with $\mathrm{AdK}^{+}$cells, has been characterized in detail [34]. We showed that a single point mutation in AdK is responsible for its novel genetic and biochemical characteristics. These mutants provide important insights and novel tools for understanding the cellular functions and regulation of the AdK isoforms in mammalian cells.

\section{Results}

\section{The AdK-L and AdK-S Isoforms Differ in their First Exons} and the Promoter Sequences

The AdK genes in human as well as rodent species are unusually large (human $546 \mathrm{~kb}$ and mouse $390 \mathrm{~kb}$ ) and they consist of 11 exons that range in length from 36 to $765 \mathrm{nt}[32,36]$. We have previously shown that the promoter for the AdK-L isoform in human, $\mathrm{CH}$ and other mammals is bidirectional and it is linked in a head-tohead fashion with the gene encoding the clathrin adaptor mu3A protein [36]. The first exon of the AdK-L isoform contains the sequence information distinguishing it from the AdK-S isoform (Figure 1). The first exon and the promoter for the AdK-S isoform have not yet been identified. Our blast searches on the human genome with the nucleotide sequence specific for the AdK$S$ isoform and its upstream non-coding region [37] have revealed that it matches perfectly with a sequence within the first intron of the AdK-L isoform. This sequence region encodes for all amino acids that are distinctive of the AdK-S isoform (Figure 1, lower part). The analysis of the 3-4 kb region upstream of the AdK-S coding sequence using the EMBOSS program [38] indicates the presence of a promoter about $350 \mathrm{bp}$ upstream of the initiator codon. This predicted promoter is located 


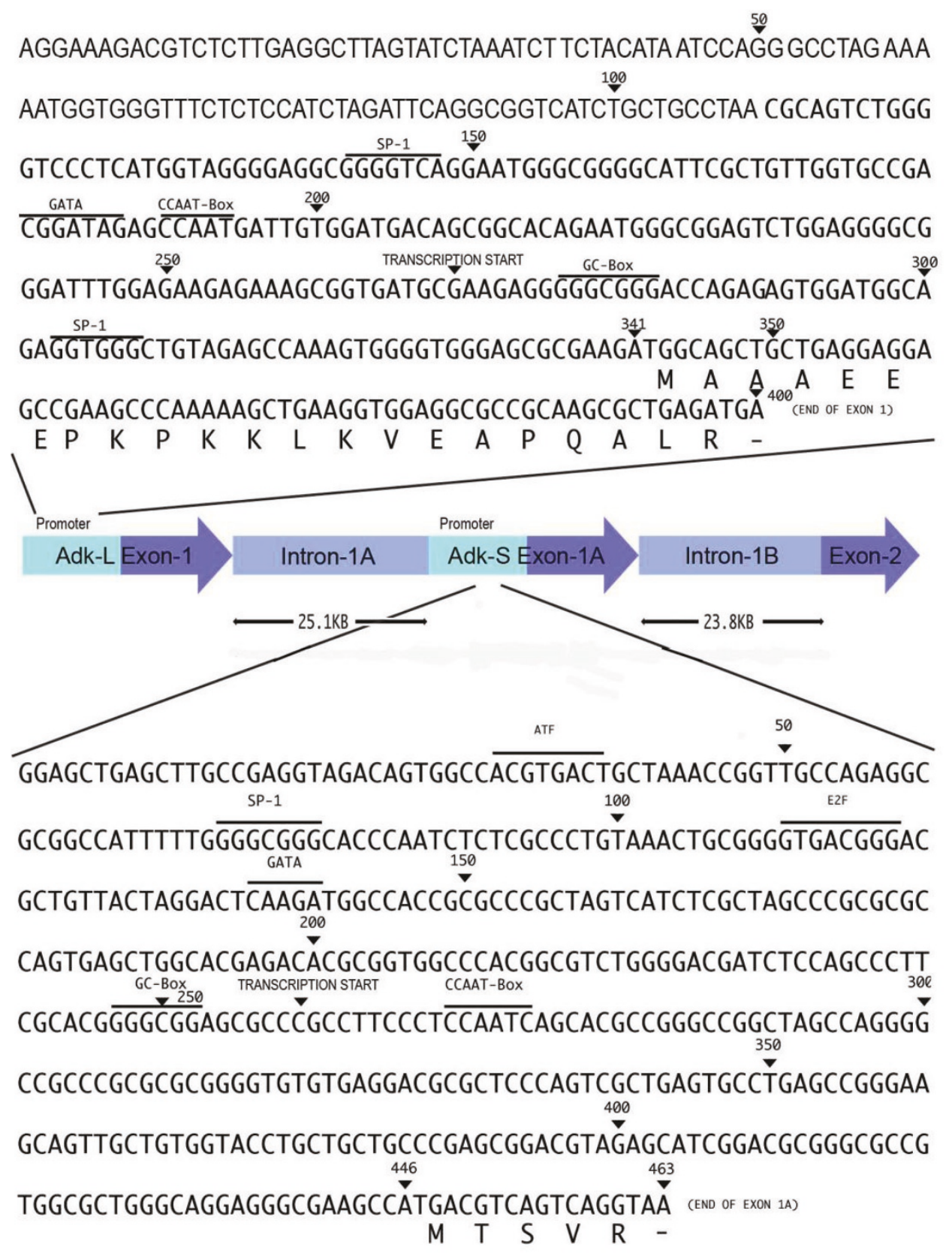

Figure $1 \mathrm{~A}$ schematic drawing showing the genomic organization of the first exons and promoter regions for the AdK-L and AdK-S genes in the human genome. The AdK gene (both AdK- $L$ and AdK-S isoforms) in human is comprised of 11 exons. Except for the first exons, all the remaining exons (not shown here) are common to these isoforms. The Exon-1 and promoter region for the AdK-L isoform were identified in earlier work [32,36]. The intron-1 for the AdK-L is now shown to contain the first exon for the AdK-S isoform. The first exons for the AdK- $L$ and AdK-S isoforms encode for all the amino acids that distinguish these two isoforms. The upstream regions of both exons contain binding sites for several transcriptional factors, only some of which are shown here. The introns and exons are not drawn to the scale in this diagram.

within a CpG island and several transcription factor binding sites are present in its proximity (Figure 1). Studies to determine the promoter activity of this region and the significance of various regulatory elements present in its vicinity will be undertaken in future. Because the AdK-L and AdK-S isoforms are identical except for the amino acids encoded by their first exons, the observed structural organization of the AdK gene indicates that the two AdK isoforms arise by differential splicing of their unique first exons with the other AdK exons. The fact that each of these exons has their own promoters strongly suggests that the expression of the 


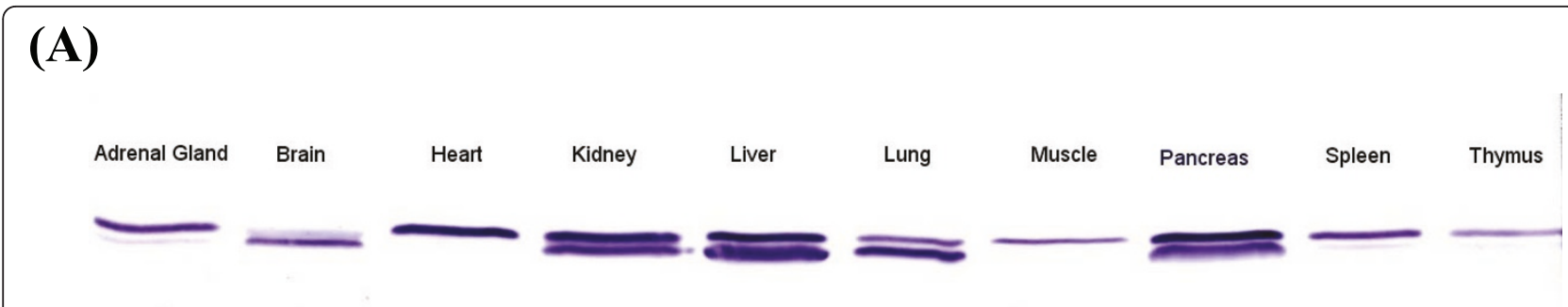

(B)

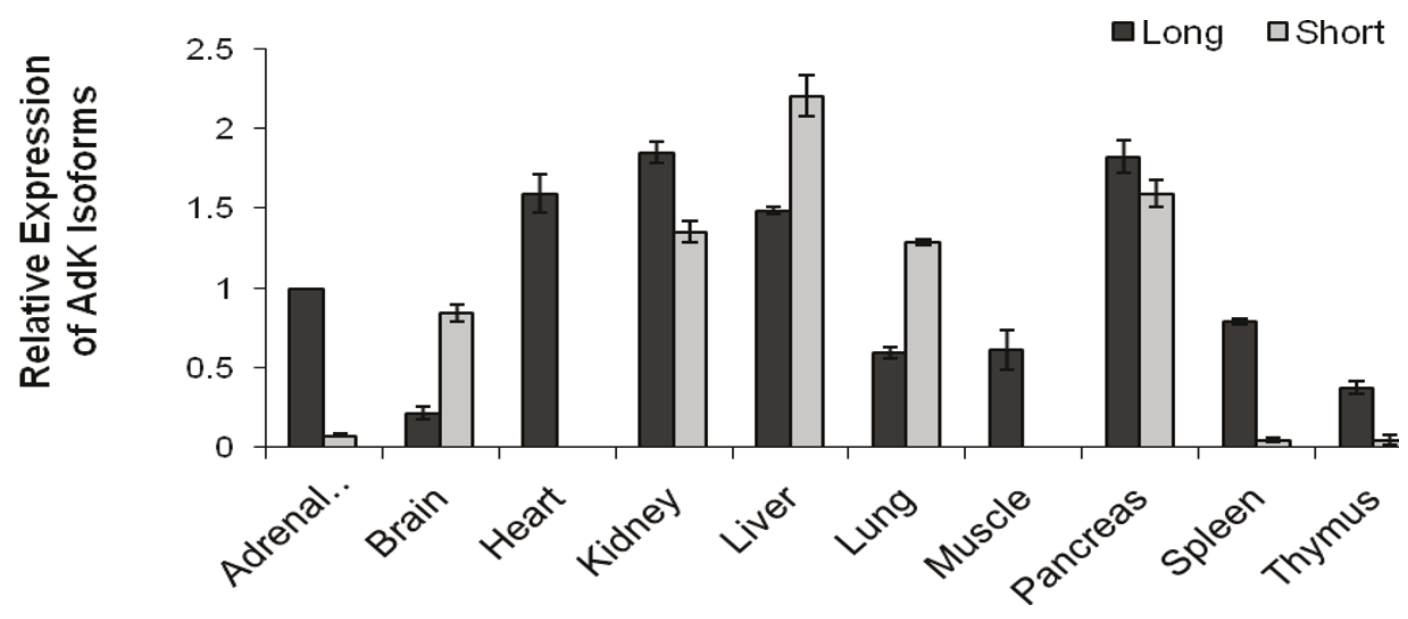

(C)

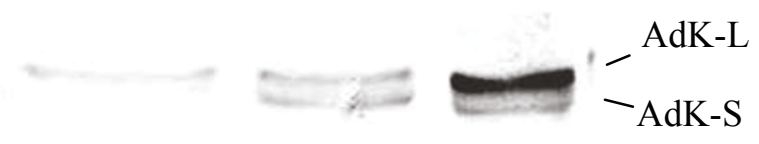

\section{CHO GM7S V79}

Figure 2 Differences in expression of two AdK isoforms in various tissues and cell lines. (A) Western blot showing the expression profile of the two isoforms in various rat tissues; (B) Quantification of the relative amounts of two AdK isoforms in rat tissues. Expression levels of the two isoforms were normalized relative to AdK-L level in adrenal gland and the average amount (intensity) \pm SD for three independent experiments is shown. (C) Western blot showing relative expression of the two isoforms in CH CHO, V79 and GM7S cell lines.

two AdK isoforms is independently regulated at the transcriptional level.

\section{Expression of the Two Isoforms Differ in Various Tissues and Cell Lines}

The expression profile of AdK in rat tissues was examined by Western blotting (Figure 2A). In immunoblots of different tissue extracts, the antibody to AdK detected only two closely related protein species of molecular masses $(\mathrm{Mr} \approx 40-42 \mathrm{KDa})$, which correspond to the two isoforms of AdK. In contrast to an earlier study, where three isoforms of AdK were reported [22], no third isoform was detected in our study. The expression of the two AdK isoforms varied markedly among different tissues. In liver, kidney, lung and pancreas both isoforms were expressed in comparable amounts (Figure 2A and $2 B$ ). In contrast, in heart, thymus and skeletal muscle, expression of mainly the AdK-L isoform was observed. Of the different tissues examined, brain was the only tissue where the short isoform was predominantly expressed (Figure 2A and 2B) [12]. The expression of the two AdK isoforms was also examined in a number 
of other mammalian cell lines. In contrast to the $\mathrm{CHO}$ lines that expressed mainly the AdK-L isoform, in the CH V79 and GM7 cell lines derived from embryonic lung [39], both AdK-L as well as AdK-S isoforms were expressed (Figure $2 \mathrm{C}$ ). The expression of the two isoforms was comparable in the GM7S cells, whereas in V79 cell line the AdK-L isoform showed slightly higher expression. In our earlier work, the human Hela cells also showed expression of only the AdK-L isoform, whereas in human HT-1080 cell line and mouse LM (TK $\left.{ }^{-}\right)$cells, both AdK isoforms were expressed in comparable amounts [27].

\section{Isolation and Characterization of Mutants Resistant to Adenosine Analogs from V79 Cells}

To gain insights into the cellular functions of AdK and the regulation of its isoforms, mutants resistant to the Ado analogs tubercidin and formycin A (FoA) were selected from V79 cells. Of these analogs, tubercidin (and also toyocamycin) similar to adenosine is an $\mathrm{N}$ nucleoside, whereas FoA is a C-nucleoside analog. In our earlier work, interesting differences have been observed in the cross-resistance patterns of AdK mutants towards the $\mathrm{N}$ - and $\mathrm{C}$ - Ado analogs [31,34]. Under the conditions employed (see Methods section), the resistant mutants were obtained at a frequency of $\sim$ $2.5 \times 10^{-7}$.

The degree of resistance of the mutants towards FoA and tubercidin was determined in comparison to the parental V79 cells. In the presence of FoA, the colony forming ability of WT V79 or CHO cells decreased sharply at drug concentrations between $5-10 \mathrm{ng} / \mathrm{ml}$ and no colonies were obtained at $20 \mathrm{ng} / \mathrm{ml}$. For tubercidin, the colony forming ability of the WT cells decreased sharply between $2-5 \mathrm{ng} / \mathrm{ml}$ and no colonies were observed at $20 \mathrm{ng} / \mathrm{ml}$. Based on these studies, the $D_{10}$ values of the WT V79 cells for FoA and tubercidin were approximated to be $10 \mathrm{ng} / \mathrm{ml}$ and $5 \mathrm{ng} / \mathrm{ml}$, respectively (Table 1). The degree of resistance of the mutant cell lines in comparison to the parental sensitive cell line was determined based on the ratios of their $D_{10}$ values [40]. Based on their relative resistance to FoA and tubercidin, the different mutants that we have isolated could be divided into two groups (Table 1). All four $\mathrm{Tub}^{\mathrm{R}}$ mutants (VT2 -5) and ten Fom ${ }^{\mathrm{R}}$ mutants viz. VF2-8, VF20, VF24, and VF26, which exhibited $>50$-fold resistance to both FoA and tubercidin formed the first group. The resistance levels of these mutants to these analogs is similar to that for the toyocamycin and tubercidin resistant mutant of $\mathrm{CHO}$ cells (including the Toy $^{\mathrm{R}}-4$ and DrToy ${ }^{\mathrm{R}}-18$ ) isolated previously $[29,41]$. In contrast to these mutants, ten other Fom ${ }^{\mathrm{R}}$ mutants (VF1, VF9-13, VF15, VF18, VF19 and VF23) were between 10-50 fold resistant to FoA, but only showed
Table 1 Degree of Resistance of Mutants Cell Lines to Adenosine Analogs

\begin{tabular}{|c|c|c|}
\hline \multirow[t]{2}{*}{ V79 Cell Line } & \multicolumn{2}{|c|}{ Relative Resistance of the Mutant Cell lines } \\
\hline & Formycin A & Tubercidin \\
\hline WT (A) & $1(\sim 20 \mathrm{ng} / \mathrm{ml})$ & $1(\sim 10 \mathrm{ng} / \mathrm{ml})$ \\
\hline $\operatorname{Tub}^{\mathrm{R}} 2(\mathrm{~A})$ & $>50$ & $>50$ \\
\hline $\mathrm{Tub}^{\mathrm{R}} 3(\mathrm{~A})$ & $>50$ & $>50$ \\
\hline $\mathrm{Tub}^{\mathrm{R}} 4$ (A) & $>50$ & $>50$ \\
\hline $\operatorname{Tub}^{R_{5}}$ (A) & $>50$ & $>50$ \\
\hline Fom $^{R} 2(A)$ & $>50$ & $>50$ \\
\hline $\mathrm{Fom}^{\mathrm{R}} 3(\mathrm{~A})$ & $>50$ & $>50$ \\
\hline Fom $^{R} 4(A)$ & $>50$ & $>50$ \\
\hline Fom $^{R} 5(A)$ & 50 & $>50$ \\
\hline Fom $^{\mathrm{R}} 6(\mathrm{~A})$ & $>50$ & $>50$ \\
\hline $\mathrm{Fom}^{\mathrm{R}} 7(\mathrm{~A})$ & $>50$ & $>50$ \\
\hline $\mathrm{Fom}^{\mathrm{R}} 8(\mathrm{~A})$ & $>50$ & $>50$ \\
\hline Fom $^{\mathrm{R}} 20(\mathrm{~A})$ & $>50$ & $>50$ \\
\hline Fom $^{R} 24(A)$ & $>50$ & $>50$ \\
\hline Fom $^{\mathrm{R}} 26(\mathrm{~A})$ & $>50$ & $>50$ \\
\hline Fom $^{\mathrm{R}} 1$ (B) & 25 & 2 \\
\hline Fom $^{R} 9$ (B) & 50 & 5 \\
\hline Fom $^{\mathrm{R}} 10$ (B) & 50 & 5 \\
\hline Fom ${ }^{\mathrm{R}} 11$ (B) & 50 & 5 \\
\hline Fom $^{\mathrm{R}} 12$ (B) & $>50$ & 5 \\
\hline Fom $^{\mathrm{R}} 13$ (B) & 25 & 2 \\
\hline Fom $^{\mathrm{R}} 15$ (B) & 50 & 2 \\
\hline Fom $^{\mathrm{R}} 18$ (B) & 10 & 1 \\
\hline Fom $^{\mathrm{R}} 19$ (B) & $>50$ & 2 \\
\hline Fom $^{R} 23$ (B) & 50 & 2 \\
\hline WT (CHO) & 1 & 1 \\
\hline Toy $^{\mathrm{R}}-4(\mathrm{CHO})$ & $>100$ & $>100$ \\
\hline DrToy $^{\mathrm{R}}-18(\mathrm{CHO})$ & $>100$ & $>50$ \\
\hline Fom $^{\mathrm{R}}-4(\mathrm{CHO})$ & 1.5 & $>70$ \\
\hline
\end{tabular}

The degree of resistance of various cell lines towards formycin A and tubercidin was determined as described in Materials and Methods. Assuming the $D_{10}$ values of these drugs for WT V79 cells as 1 , the relative resistance of the mutant cell lines was calculated. (A) and (B) refer to the two class of mutants of V79 cells.

minimal (2-5 fold) resistance to tubercidin. The drugresistance profile of these mutants (Group B) is similar to that of the Fom ${ }^{\mathrm{R}}-4$ mutant of $\mathrm{CHO}$ cell isolated in earlier work [34].

To determine if these mutants were affected in the expression of the AdK isoforms, Western blot analysis was performed (Figure 3 ). Two closely migrating protein bands with molecular masses of $\sim 40-42 \mathrm{kDa}$ corresponding to the two AdK isoforms were detected in the WT V79 cells and a number of mutants (VF8, VF15, VF18, VF19, VF20, VF24, VF26 and VT2 and VT3). However, large differences were observed in various 


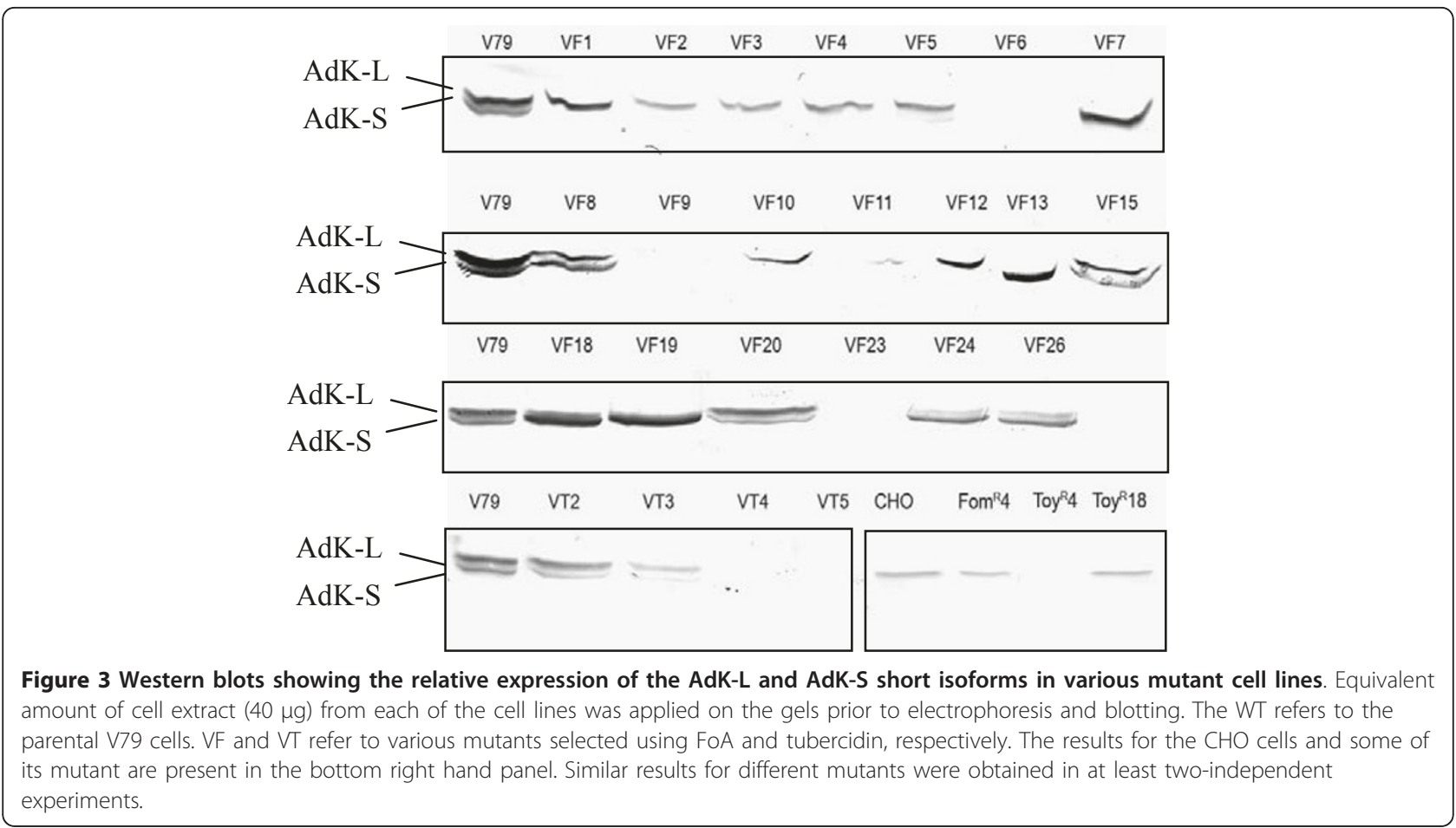

mutants with regard to expression level of the two isoforms. VF13 mutant expresses only the AdK-S isoform, whereas in VF1-4 and VF10-12 mutants only the AdK-L isoform was found. In contrast to these mutants, several other mutants such as VT4, VT5, VF6, VF9 and VF23 showed no expression of either of the two AdK isoforms. Some of the other mutants including VF18, VF19, VF24 and VF26, also showed higher expression of the AdK-S isoform. Western blot analysis was also performed on some of the mutants of $\mathrm{CHO}$ cells that are studied in this work (Figure 3, bottom right hand panel). In the three mutants isolated from the $\mathrm{CHO}$ cells, which express only the AdK-L isoform, no cross-reactive protein was observed in the Toy $^{\mathrm{R}}-4$ mutant, whereas the DrToy ${ }^{\mathrm{R}}-18$ and Fom ${ }^{\mathrm{R}}-4$ mutants showed similar expression of the AdK-L isoform as the WT cells.

The most common mechanism for resistance to Ado analogs involves deficiency or loss of AdK activity. Hence, AdK activity in the cell extracts of various mutants was measured and normalized with respect to both protein and AdK activity in the WT V79 cells. A summary of these results is presented in Figure 4. The cell extracts from twelve mutants (VT2-5 and VF2-4, VF6, VF7, VF9, VF24 and VF26) contain negligible (0.5$3 \%)$ AdK activity. The cell extracts from eleven other mutants (VF1, VF5, VF8, VF10-13, VF15, VF20 and VF23) contain low (6-15\%), but significant level of AdK activity (Figure 4). In contrast to these mutants that contain either no or very low level of AdK activity, two other mutants VF18 and VF19 contain significantly higher amounts of AdK activity than in the WT V79 cells. The AdK activity was also examined in the three AdK mutants of $\mathrm{CHO}$ cells. All three of these mutants $\mathrm{i}$. e. Toy $^{\mathrm{R}}-4, \operatorname{DrToy}^{\mathrm{R}}-18$ and Fom ${ }^{\mathrm{R}}-4$ contain only background activity (i.e. $\approx 0.5-1 \%$ of the WT level). Of these mutants, the $\mathrm{Toy}^{\mathrm{R}}-4$ contains a large deletion in the AdK gene. Hence, this level of background activity seen in the cell extracts of many mutants (Figure 4) is not due to AdK but it is possibly due to activities of other enzymes in cell extracts $[24,29,32]$.

\section{Molecular Characterization of the Mutants affected in AdK}

The mutants of $\mathrm{CHO}$ cells lacking in AdK activity that have been previously studied contained large deletions in the AdK gene [32] and they provided no useful information regarding structure-activity aspects of AdK. With the availability of a good antibody to AdK, the mutants lacking AdK antibody cross-reactive bands can now be readily identified and excluded from further analyses. These studies have revealed that the mutants DrToy $^{\mathrm{R}}-18$ and Fom ${ }^{\mathrm{R}}-4$ isolated in our earlier work both contained normal amounts of the AdK antibody cross-reactive bands (see Figure 3). Hence, these mutants and two other mutants VF18 and VF19 obtained in this work were further characterized.

Of these mutants, the mutant Fom $^{\mathrm{R}}-4$ is of particular interest. This mutant is highly resistant to FoA and 


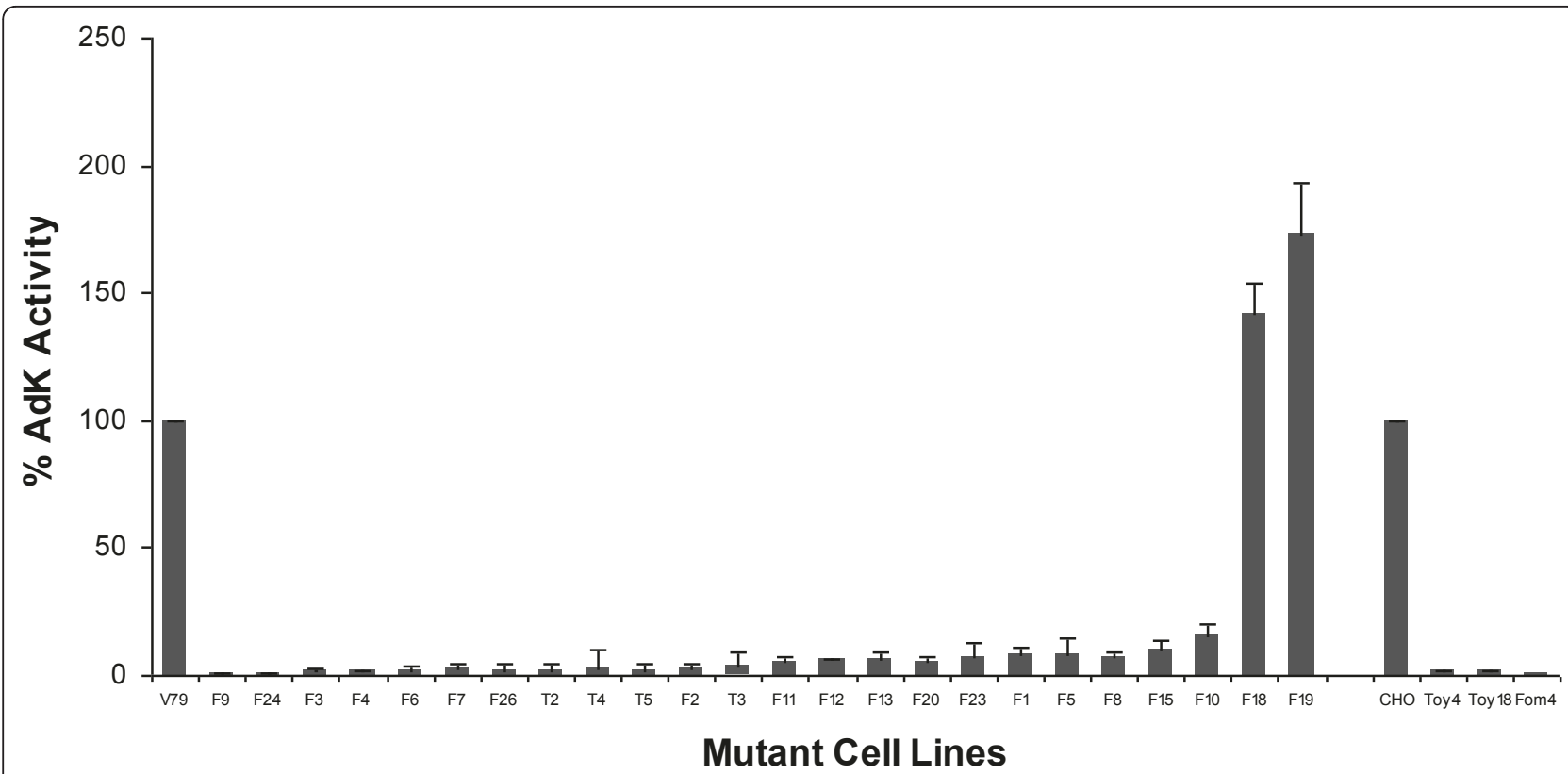

Figure 4 AdK activity in the parental and mutant cell lines. The protein concentration in all cell extracts was adjusted to be the same (1 $\mathrm{mg} / \mathrm{ml}$ ). Assuming the AdK activity in the parental V79 cells to be 100, the relative amount (\%) of AdK activity in various mutants was determined. The results are average of at least 2 independent measurements.

other C-Ado analogs, but shows very little or no resistance to various N-Ado analogs including toyocamycin and tubercidin $[31,34,41]$. Interestingly, although this mutant was able to phosphorylate adenosine and various $\mathrm{N}$-Ado analogs in vivo, the cell extracts from this mutant showed no AdK activity and all efforts to detect/recover AdK activity in its cell extracts have been unsuccessful [34]. Another novel aspect of this mutant is that its drug resistance phenotype expresses dominantly in cell hybrids formed with the WT CHO cells [34], which is in contrast to the recessive behaviour of all other $\mathrm{AdK}^{-}$mutants that have been studied $[29,41,42]$. Hence, it was of much interest to determine the nature of the molecular alteration in this mutant. To characterize the molecular alterations in this and other mutants, full-length AdK sequences from the mutant cDNA were PCR amplified and sequenced. Of the four independent clones from the Fom ${ }^{\mathrm{R}}-4$ mutant that were sequenced, all were found to contain a single $\mathrm{C} \rightarrow \mathrm{T}$ mutation that changed a conserved Ser residue at position 191 into phenylalanine. The changed amino acid corresponds to position 175 in the human AdK structure (Figure 5A) [43,44]. To confirm the significance of this molecular alteration for the biochemical and drug-resistance phenotype of the Fom ${ }^{\mathrm{R}}-4$ mutant, the mutation causing $\mathrm{S}_{191} \rightarrow \mathrm{F}$ alteration was introduced by site-directed mutagenesis into the WT $\mathrm{CH}$ (or human) AdK in the mammalian expression vector pcDNA3.1. The WT CHO cells and an AdK' mutant of
CHO cell $\left(\right.$ Toy $\left.^{\mathrm{R}}-4\right)$ were transformed with this plasmid DNA and stable transformants were selected in presence of the neomycin analog G418. The degree of resistance of these transformants as well as the WT CHO, Fom ${ }^{\mathrm{R}}-4$ and $\mathrm{Toy}^{\mathrm{R}}-4$ cell lines towards tubercidin and FoA was determined.

The results of these experiments are shown in Figure 6. As expected, the WT CHO cells were sensitive to both tubercidin and FoA, whereas the Toy ${ }^{\mathrm{R}}-4$ mutant containing a deletion in the AdK gene was highly resistant to both of them. Further, as reported in our earlier work [34], the Fom ${ }^{\mathrm{R}}-4$ mutant was highly resistant to FoA but it displayed negligible resistance to tubercidin. The transformants obtained upon transfection of WT cells with the $\operatorname{AdK}\left(\mathrm{S}_{191} \mathrm{~F}\right)$ plasmid were interesting since they also exhibited resistant to FoA but were sensitive to tubercidin. Because WT CHO cells contained normal AdK, the FoA resistance of these transformants indicated that the mutant $\operatorname{AdK}\left(\mathrm{S}_{191} \mathrm{~F}\right)$ was able to confer resistance despite the presence of wild-type AdK. The results obtained upon transformation of the $\mathrm{Toy}^{\mathrm{R}}-4$ mutant with the $\operatorname{AdK}\left(\mathrm{S}_{191} \mathrm{~F}\right)$ plasmid were equally interesting. Although the $\mathrm{Toy}^{\mathrm{R}}-4$ mutant is highly resistant to both tubercidin and FoA, the transformants obtained in this case were found to be only marginally resistant to tubercidin and they displayed similar level of resistance to FoA as the Fom ${ }^{\mathrm{R}}-4$ mutant. These results indicate that the expression of the $\operatorname{AdK}\left(\mathrm{S}_{191} \mathrm{~F}\right)$ plasmid has made the Toy ${ }^{R}-4$ cells sensitive towards tubercidin, 


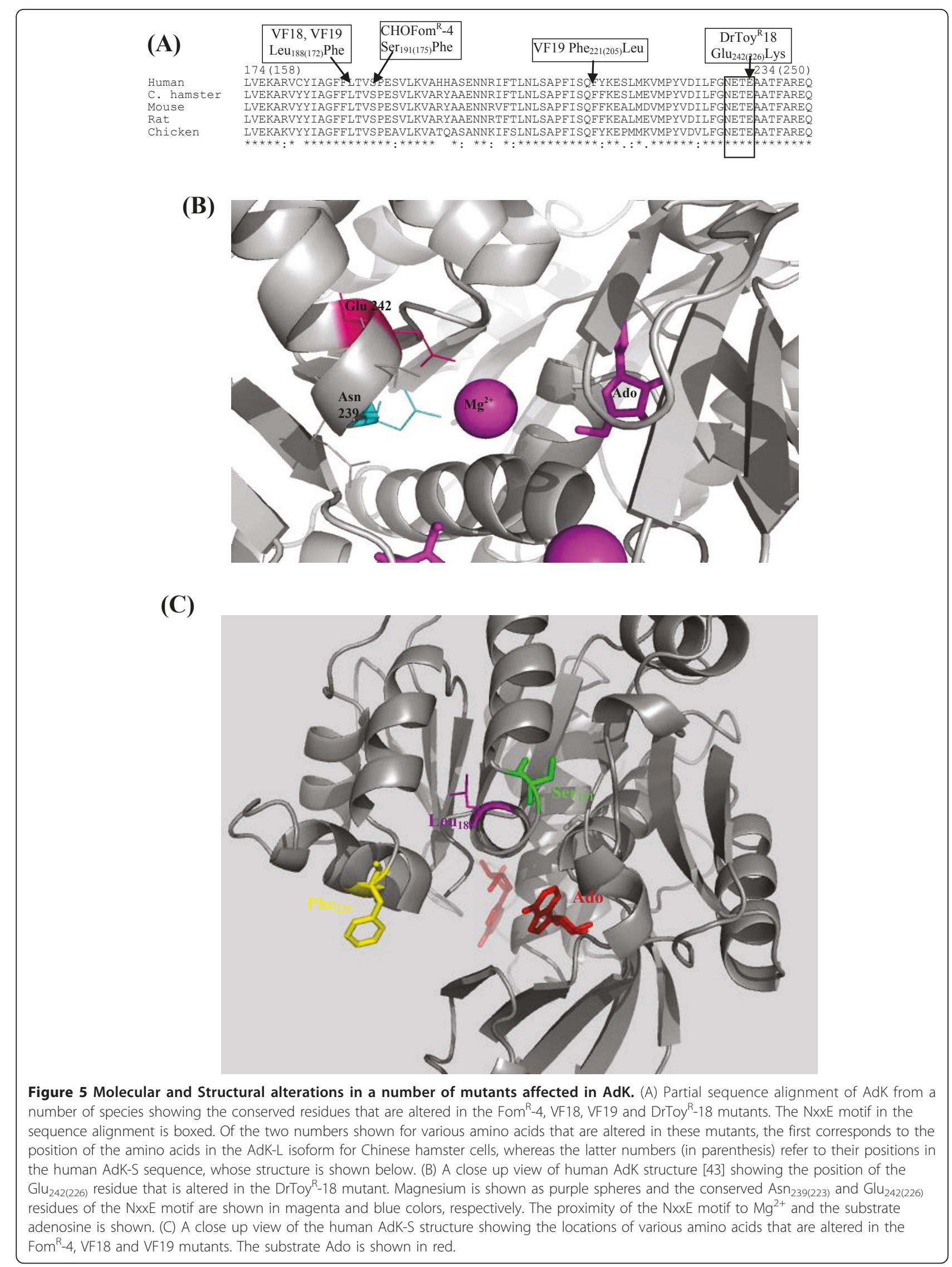




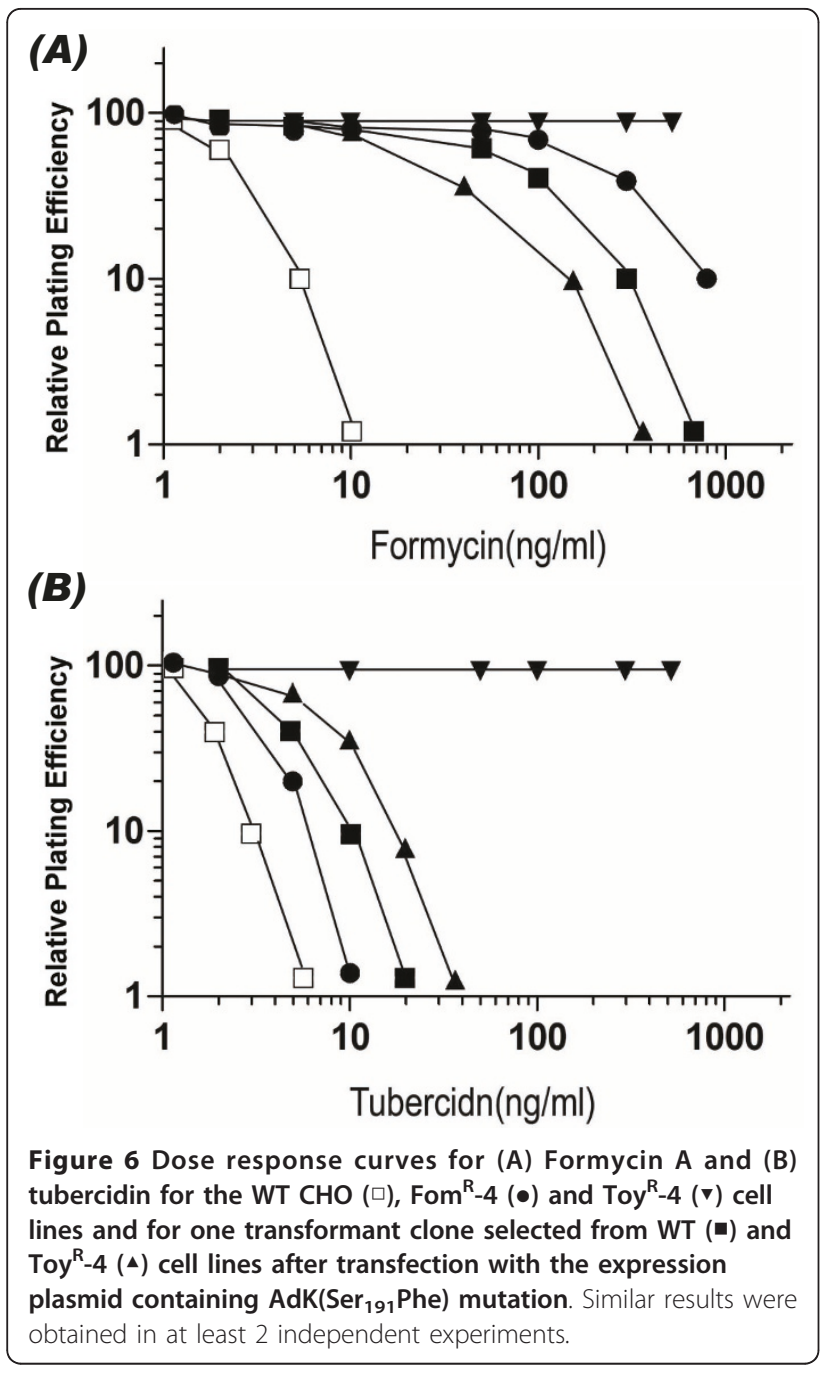

while maintaining resistance towards formycin A. These results provided strong evidence that the $S_{191} \mathrm{~F}$ mutation in the AdK was behaving dominantly and it was responsible for the novel genetic and biochemical properties of the Fom ${ }^{\mathrm{R}}-4$ mutant.

The DrToy ${ }^{\mathrm{R}}-18$ mutant is highly resistant to both $\mathrm{N}$ and $\mathrm{C}$ - adenosine analogs. The sequencing of AdK cDNA from this mutant revealed that it contained a single point mutation ( $\mathrm{G} \rightarrow$ A substitution), which changes a conserved $\mathrm{Glu}_{242}$ residue in the NxxE motif to Lys (Figure 5A). Earlier studies indicate that the conserved Asn and Glu residues in the NxxE motif (boxed in Figure 5A) are involved in the binding of activating phosphate ion, indicating that this motif is essential for AdK function $[1,45]$. We have also introduced the $E_{242} \mathrm{~K}$ mutation in $\mathrm{CHO}$ AdK cDNA in pET-15b expression vector [45]. Upon expression, the resulting protein showed no AdK activity (results not shown) confirming that this mutation leads to the inactivation of the enzyme and is responsible for the drug resistance phenotype of the DrToy ${ }^{\mathrm{R}} 18$ mutant. These results provide strong evidence that the NxxE motif is essential for AdK function in vivo.

The AdK cDNA was also PCR sequenced from the VF18 and VF19 mutants. For VF18 mutant, of the four clones sequenced, 2 contained a single point mutation changing the $\mathrm{Leu}_{188}$ into Phe. The remaining two clones showed no change in the AdK sequence. Similarly, of the 4 clones that were sequenced from the VF19 mutant, 2 contained the same mutation ( $\mathrm{Leu}_{188} \mathrm{Phe}$ ) as observed in the VF18 mutant. However, these clones in addition also contained a second mutation changing $\mathrm{Phe}_{221}$ into Leu. The mutant VF19 displays a higher degree of resistance to FoA in comparison to the VF18. Thus, it is possible that these two mutations synergistically reduce the binding of FoA to AdK. The locations of various amino acids that are altered in these mutants i.e. Ser $_{191}$ Phe, $\mathrm{Leu}_{188}$ Phe, Phe ${ }_{221}$ Leu and $\mathrm{Glu}_{242}$ Lys in the human AdK structure are shown in Figure $5 \mathrm{~B}$ and $5 \mathrm{C}$.

\section{Discussion and Conclusion}

This paper presents information regarding several novel characteristics of AdK from mammalian cell lines. We show that the two isoforms of AdK differ from each other only in their first exons. Because each of these isoforms contains its own promoter, the transcription of these two isoforms should be regulated independently at the genetic level. The expression of the two isoforms also differs greatly in various rat tissues. Whereas in liver, kidney, lung and pancreas both isoforms were expressed at comparable levels, in other tissues such as heart, thymus, skeletal muscle and brain, either the AdK-L or AdK-S isoform is predominantly expressed. Large differences in the expression of these two isoforms have also been observed in earlier studies $[12,22,23]$. Importantly, our studies also showed that the expression of the two isoforms also differed greatly in established cell lines. Whereas the $\mathrm{CHO}$ and Hela cells expressed only the AdK-L isoform, in two other cell lines V79 and GM7S from the same species, both AdK isoforms were expressed in comparable amounts. It is of interest that the V79 and GM7 cell lines, which are derived from lung, expresses both isoforms. Therefore, it is possible that the expression of these isoforms in cultured cells reflect their expression profiles in corresponding tissues.

However, the main focus of this work was on isolation and characterization of mutant $\mathrm{CH}$ cell lines that are affected in AdK. From CH V79 cell line expressing both AdK isoforms, 24 mutants resistant to FoA and tubercidin were isolated. About half of these mutants were highly resistant to both tubercidin and FoA, whereas the remaining, although they were highly resistant to FoA, 
exhibited only marginal resistance to tubercidin. Biochemical studies have revealed that all of these mutants except VF18 and VF19 contained either no or very low level of AdK activity. This accounts for their resistance to the Ado analogs, which are converted into their toxic forms by AdK. The expression of the two AdK isoforms in different mutants also exhibited important differences. Whereas the mutants VF6, VF9, VT4 and VT5 containing only background AdK activity lacked both isoforms, many other mutants with similar level of AdK activity expressed either the AdK-S isoform viz. VF13, VF24 and VF26 or the AdK-L isoform viz. the mutants VF1-7 and VF12. Surprisingly, the mutants VF8, VF15, VF20 and VT2 that show negligible or greatly reduced level of AdK activity expressed both AdK isoforms at a level comparable to the WT V79 cells. Although, the molecular alterations in most of these mutants remain to be identified, it is quite likely that in mutants that do not express either of these isoforms, mutations or deletions affecting one or more of the common AdK exons (exons 2-11) have occurred. These mutants could be similar to the mutants $\mathrm{CHO}$ cells that have been previously characterized, which contained large deletions leading to loss of several introns and exons [32,36]. In contrast to these mutants, the mutants where expression of either the AdK-L or AdK-S isoform is preferentially affected are most likely to contain mutations in the promoter regions for these isoforms. Thus, further molecular characterization of these mutants, such as the methylation status, should provide useful insights concerning the functional significance of the two isoforms and how their expression may be regulated in mammalian cells.

The molecular alterations in a number of mutants resistant to Ado analogs were also identified in the present studies. One of these mutants, $\operatorname{DrToy}^{\mathrm{R}}-18$ was specifically altered in the conserved NxxE motif, which has been indicated to be important in the binding of activating phosphate ion to AdK as well as other PfkB family of proteins $[1,4,45,46]$. The complete loss of AdK activity in this mutant, both in vivo and in vitro, now provides direct evidence that this motif, which is in close proximity to the binding sites for $\mathrm{Mg}^{2+}$ ion as well the substrate adenosine (Figure 5B), is essential for AdK function in vivo.

In this work, we have also identified the molecular alteration in the Fom ${ }^{\mathrm{R}}-4$ mutant, whose genetic and biochemical characteristics have remained puzzling for $>25$ years. We show that this mutant contains a single base substitution mutation that changes a conserved Ser $_{191}$ into Phe. This mutation when introduced into either $\mathrm{CH}$ or human AdK (results not shown) was sufficient to confer a similar genetic and biochemical phenotype as observed for the Fom ${ }^{\mathrm{R}}-4$ mutant. The $\mathrm{Ser}_{191}$ Phe mutation is present in the AdK structure [43] on the periphery of the protein near the entrance of the substrate-binding pocket (Figure $5 \mathrm{C}$ ). The C-Ado analogs, to whom the $\mathrm{Fom}^{\mathrm{R}}-4$ mutant exhibits selective resistance exist predominantly in Syn conformation in contrast to the Anti-conformation for Ado and various Nnucleoside analogs $[31,35]$. Hence, it is likely that this molecular alteration selectively prevents the binding of FoA and other $\mathrm{C}$-nucleosides to the mutant enzyme.

However, there are two other puzzling aspects of the Fom $^{\mathrm{R}}-4$ mutant that remain to be addressed. First, the cell extracts from this mutant show no AdK activity despite its containing AdK activity in vivo. Second, the drug-resistance phenotype of this mutant is dominant in cell hybrids formed with WT cells $[34,41]$. The first observation suggests that the reaction product of AdK i.e. AMP is not released from the mutant enzyme under in vitro conditions, but in the cellular milieu it is likely directly transferred to the next enzyme AMPkinase (AMPK) in the pathway. The AMPK, which carries out the reaction AMP $+\mathrm{ATP} \leftrightarrow 2$ ADP, plays a key role in maintaining the equilibrium concentrations of all three adenine nucleotides [47]. The subsequent phosphorylation of ADP into ATP is carried out by the enzyme nucleoside diphosphate kinase [48]. Because the toxicity of Ado analogs (e.g. FoA) requires their phosphorylation into higher phosphorylated forms (e.g. di- and tri-phosphates), which interfere with different metabolic pathways $[31,35,49]$, if the mutation in AdK prevents the conversion of FoA or FoA- $\mathrm{PO}_{4}$ into higher phosphorylated forms then their toxicity will be averted.

In view of these consideration, to account for the lack of AdK activity in the Fom ${ }^{\mathrm{R}}-4$ extracts and the dominant expression of this mutation, we postulate that the mutant AdK and the enzyme AMPK exist as a complex in cells such that the AMP formed from AdK reaction is not released but directly transferred to AMPK for conversion into ADP (Figure 7). Further, although this complex binds adenosine, N-Ado analogs and the monophosphates of $\mathrm{N}$-adenosine analogs (i.e. Toy-MP or Tub-MP) normally, it is unable to bind FoA or FoAMP as a result of the Ser $_{191}$ Phe mutation. The formation of a complex between these two enzymes will explain both the lack of AdK activity in the mutant cell extracts (as the product AMP is not released from the mutant enzyme) and also the dominant expression of FoA resistance in this mutant. In cell hybrids formed between WT and Fom ${ }^{\mathrm{R}}-4$, although the WT AdK can phosphorylate FoA, the FoA-MP formed, due to its non-recognition by the AdK-AMPK complex, is not further metabolized to higher phosphorylated forms to cause toxic effect. Thus, these cells display resistance to FoA. It should be noted that the $\operatorname{Ser}_{191}$ Phe mutation in the 


\section{(A) Wild Type}

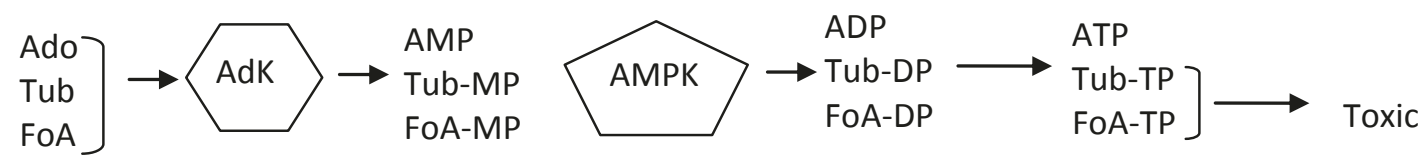

\section{(B) Fom ${ }^{\mathrm{R}}-4$ Mutant}

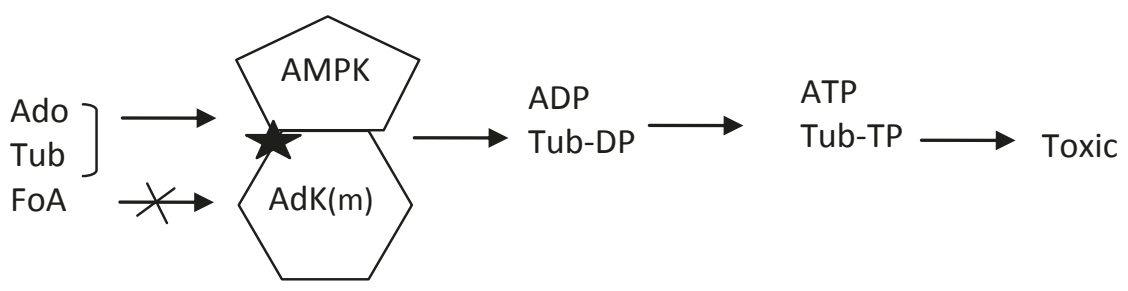

\section{(C) Hybrid Fom ${ }^{\mathrm{R}}-4$ x Wild Type}

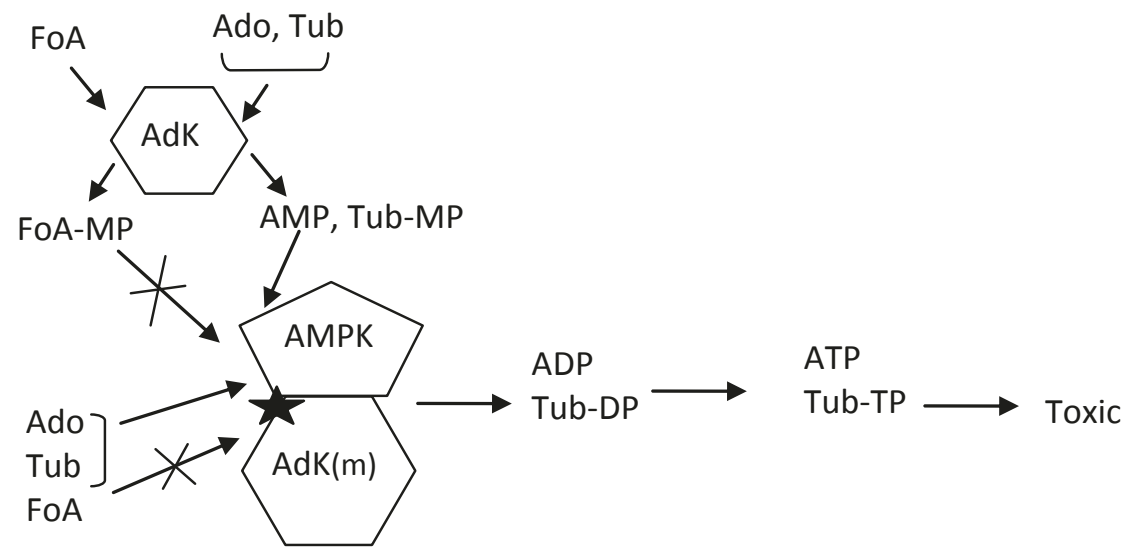

Figure $7 \mathrm{~A}$ model to account for the lack of AdK activity in the cell extracts of the Fom ${ }^{\mathrm{R}}-4$ mutant and dominant expression of its drug-resistance phenotype. (A) In the WT cells, AdK converts Ado and various Ado-analogs (e.g. FoA, Tub) into their corresponding monophosphates; subsequently AMP-kinase (AMPK) and other enzymes convert them into di- and tri-phosphates. (B) and (C), In the Fom ${ }^{\mathrm{R}}-4$

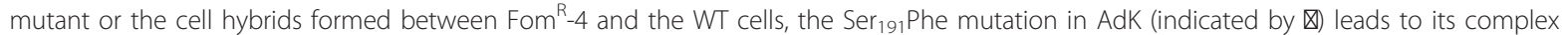
formation with AMPK. This mutation is also postulated to specifically prevent the binding of FoA and FoA-MP to the AdK-AMPK complex. As a result of this complex formation, AMP (or Tub-MP) formed by AdK is not released but directly transferred to the AMPK for conversion into ADP.

These account for the unusual properties of the Fom ${ }^{\mathrm{R}}-4$ mutant.

Fom ${ }^{\mathrm{R}}-4$ mutant is present on the surface of AdK (Figure 5C) and it replaces a hydrophilic amino acid with a hydrophobic residue thus creating a surface hydrophobic patch (denoted by $\star$ in Figure 7 ) that could be important in its complex formation with the AMPK. Although, this model is speculative, based upon our results, it is the only model that can account for the different characteristics of the Fom ${ }^{\mathrm{R}}-4$ mutant, which has remained an enigma for $>25$ years. However, this model makes a number of predictions, which will be experimentally tested, providing further insights into the cellular function of this enzyme. 
Lastly, we have also identified the molecular alterations in two of the V79 cell mutants, V18 and VF19, which similar to the $\mathrm{Fom}^{\mathrm{R}}-4$ mutant also exhibit preferential resistance to the C-Ado analogs. The observed molecular alterations in these two mutants are located on the same face of AdK as the mutation in the Fom ${ }^{\mathrm{R}}-4$ mutant (Figure 5C). Thus, it is likely that the genetic changes in these mutants, $\mathrm{Leu}_{188} \mathrm{Phe}$ and $\mathrm{Phe}_{221} \mathrm{Leu}$, also selectively affect the binding of FoA to the mutant AdK. However, it is of interest that of the four clones that were sequenced for these mutants, only two contained mutational alterations, whereas the other two showed no change. This is in contrast to the Fom ${ }^{\mathrm{R}}-4$ mutant, where all four sequenced clones contained the $\mathrm{Ser}_{191}$ Phe mutation. Earlier work on $\mathrm{CHO}$ and V79 cells has provided evidence that the $\mathrm{CHO}$ cell line is functional hemizygous for many genetic loci including the AdK gene, whereas in V79 cells two functional copies of these genes were inferred [29,50]. In this context, our observations that in the Fom ${ }^{\mathrm{R}}-4$ cells only the mutated form of AdK was found, whereas in mutant V79 cells both WT and the mutated forms of AdK were present support to this inference. The fact that the VF18 and VF19 mutants are resistant to FoA, despite their containing normal levels of AdK activity, indicates that the mutations in them are also expressing codominantly.

The mutants VF18 and VF19 are also of much interest, because in comparison to all other AdK mutants, they are the only mutants exhibiting enhanced AdK activity relative to the parental V79 cells. These mutants also show higher expression of the AdK-S isoform in comparison to the AdK-L isoform. These observations indicate that these mutants, in addition to the molecular changes that we have identified in this work, also contain additional genetic changes affecting the expression of the two isoforms. To understand the functional significance of different molecular alterations in these mutants, it is of much interest to further characterize AdK from these mutants at genetic, molecular and biochemical levels.

\section{Methods}

\section{Cell Culture and Cell Lines}

The origins of various $\mathrm{CH}$ cell lines $\mathrm{CHO}, \mathrm{V} 79$ and GM7S used in this work have been described in earlier work $[29,39]$. The Toy ${ }^{\mathrm{R}}-4$, DrToy $^{\mathrm{R}}-18$ and Fom ${ }^{\mathrm{R}}-4$ mutants of $\mathrm{CHO}$ cells were also isolated and partially characterized in earlier work $[24,32,34]$. Of these Toy $^{\mathrm{R}}-4$ and DrToy ${ }^{\mathrm{R}}-18$ mutants are highly resistant to both $\mathrm{N}$ and C-Ado analogs. The mutant DrToy ${ }^{\mathrm{R}}-18$ was obtained from the Dr-31 cell line, which is a different clone of the original CHO cell line [29]. The Toy ${ }^{\mathrm{R}}-4$ mutant has previously been shown to contain a large deletion in the AdK gene $[24,29,32]$, whereas the genetic lesion in $\operatorname{DrToy}^{\mathrm{R}}-18$ has not yet been identified. The Fom $^{\mathrm{R}}-4$ mutant was selected using FoA and its various characteristics are described in earlier work [34,41]. The cells were grown in monolayer culture at $37^{\circ} \mathrm{C}$ in alpha medium supplemented with $5 \%$ fetal bovine serum in $95 \%$ air $-5 \% \mathrm{CO}_{2}$ atmosphere. For selection of mutants, V79 cells were treated with $300 \mu \mathrm{g} / \mathrm{ml}$ of the mutagen ethyl methanesulfonate for $18 \mathrm{hrs}$ and then grown for 5 days [29]. The mutants were selected by plating $5 \times 10^{5}$ cells/dish in multiple dishes in medium containing either $200-500 \mathrm{ng} / \mathrm{ml}$ FoA $(+10 \mu \mathrm{g} / \mathrm{ml}$ of the adenosine deaminase inhibitor erythro-9-(2-hydroxy-3-nonyl)adenine) or $80 \mathrm{ng} / \mathrm{ml}$ tubercidin. The mutant colonies were expanded and maintained by growth in non-selective medium. The mutants were named based on the selective drug. Thus, V79Fom ${ }^{\mathrm{R}}$ and $\mathrm{V} 79 \mathrm{Tub}^{\mathrm{R}}$ (annotated as VF and VT) denote mutants isolated using FoA and tubercidin. The degree of resistance of the cell lines towards Ado analogs was determined by plating 200 and 500 cells in medium containing different concentrations of the analogs as in earlier work [29,34]. After 7 days, the colonies were fixed, stained with $0.5 \%$ methylene blue and their numbers were counted. Assuming the number of colonies formed in the absence of any drug to be $100 \%$, the relative plating efficiencies of cell lines in presence of different drug concentrations were determined. The $\mathrm{D}_{10}$ value represents the drug concentration that reduces plating efficiency of a cell line to $10 \%$ of that observed in the absence of any drug [40]. The sources of various Ado analogs and other chemicals have been described in earlier work $[29,34]$.

\section{Adenosine kinase activity assay, Western blotting, RT-PCR and Sequencing}

AdK activity was measured as described previously using a radioactive assay involving conversion of $\left[{ }^{3} \mathrm{H}\right]$-adenosine to $\left[{ }^{3} \mathrm{H}\right]$-AMP $[29,45]$. $\left[2,8-{ }^{3} \mathrm{H}\right]$-Adenosine $(40 \mathrm{Ci} /$ mmol) was purchased from American Radiolabeled Chemicals Inc. For Western blot analysis, $40 \mu \mathrm{g}$ of cell extracts from different cell lines were electrophoresed on $12 \%$ sodium dodecyl sulfate polyacrylamide gels (SDS-PAGE). After transfer to nitrocellulose and blocking, the blot was reacted with 1:1000 dilution of a rabbit polyclonal antibody to human recombinant AdK raised in our lab [27]. After washing the blot was reacted with 1:2000 dilution of anti-rabbit lgG conjugated to horseradish peroxidase and then developed using 4-Chloro-1naphthol and $\mathrm{H}_{2} \mathrm{O}_{2}$. All of the experiments were repeated at least twice with very similar results. The quantification of the results for the rat tissue experiments (three independent experiments) was carried out using the NIH ImageJ software and the average intensity \pm SD was calculated. For RT-PCR, total RNA was isolated from 1-2 confluent dishes using TRIzol 
(Invitrogen) as per the manufacturer's protocol. cDNA was generated using RevertAid ${ }^{\mathrm{TM}} \mathrm{H}$ Minus First Strand cDNA Synthesis Kits (Fermentas) with oligo(dT)18 primers. Full length AdK sequence was amplified from the cDNA using the forward primer 5'ATGGCAGCTGCTGAGGAGC-3' and reverse primer 5'-TCAGTGGAAGTCTGGCTTCTC-3' based on CH AdK sequence [26]. The amplified fragments were cloned and sequenced using the M13 forward and reverse primers.

\section{Mammalian Cell Transfection and In vitro Mutagenesis} The full-length AdK cDNA (long isoform) from $\mathrm{CH}$ was cloned in the mammalian cell expression vector pcDNA3.1 [26]. The $\mathrm{S}_{191} \rightarrow \mathrm{F}$ mutation in the $\mathrm{CH}$ (or human) cDNA was made using the 'Quickchange' sitedirected mutagenesis kit (Stratagene) as described in earlier work $[27,45]$. The transfection of the wild-type (WT) or the mutant $\mathrm{Toy}^{\mathrm{R}}-4 \mathrm{CHO}$ cells with these plasmid DNAs was carried out using the Lipofectamin-2000 reagent (Invitrogen) as described in earlier work [27]. Stable transfectants expressing these genes were obtained by growing the cells in presence of G-418 (650 $\mu \mathrm{g} / \mathrm{ml}$ ) for more than 1 month. The degree of resistance of these transformants for tubercidin and FoA was determined as described above.

\section{Acknowledgements}

This work was supported by a research grant (T-6177) from the Heart and Stroke Foundation of Canada.

\section{Authors' contributions}

XAC and TA carried out selection of various mutants of V79 cells and crossresistance studies, enzyme activity assay and immunoblot analyses on them. $X A C$ and BS were responsible for examining the tissue distribution of AdK and for molecular characterization of the mutants. BS was responsible for identifying the promoter region for the AdK-S isoform, for creation of sitedirected mutants and for transformation studies on them. RSG was responsible for conceiving and directing this study and for writing the manuscript, which has been seen and approved by all authors.

Received: 16 November 2010 Accepted: 17 May 2011

Published: 17 May 2011

\section{References}

1. Park J, Gupta RS: Adenosine kinase and ribokinase-the RK family of proteins. Cell Mol Life Sci 2008, 65:2875-2896.

2. Bork P, Sander $C$, Valencia A: Convergent evolution of similar enzymatic function on different protein folds: the hexokinase, ribokinase, and galactokinase families of sugar kinases. Protein Sci 1993, 2:31-40.

3. Miller RL, Adamczyk DL, Miller WH, Koszalka GW, Rideout JL, Beacham LM III, Chao EY, Haggerty JJ, Krenitsky TA, Elion GB: Adenosine kinase from rabbit liver. II. Substrate and inhibitor specificity. J Biol Chem 1979, 254:2346-2352.

4. Cabrera R, Babul J, Guixe V: Ribokinase family evolution and the role of conserved residues at the active site of the PfkB subfamily representative, Pfk-2 from Escherichia coli. 2010, PMID 2259967.

5. Mullane K, Bullough D: Harnessing an endogenous cardioprotective mechanism: cellular sources and sites of action of adenosine. J Mol Cell Cardiol 1995, 27:1041-1054.

6. Boison D: Adenosine kinase, epilepsy and stroke: mechanisms and therapies. Trends Pharmacol Sci 2006, 27:652-658.
7. Bontemps F, Mimouni M, Van den BG: Phosphorylation of adenosine in anoxic hepatocytes by an exchange reaction catalysed by adenosine kinase. Biochem J 1993, 290(Pt 3):679-684.

8. Peart J, Flood A, Linden J, Matherne GP, Headrick JP: Adenosine-mediated cardioprotection in ischemic-reperfused mouse heart. J Cardiovasc Pharmacol 2002, 39:117-129.

9. Mubagwa K, Flameng W: Adenosine, adenosine receptors and myocardial protection: an updated overview. Cardiovasc Res 2001, 52:25-39.

10. Mangoni ME, Barrere-Lemaire S: Adenosine receptors, heart rate, and cardioprotection. Cardiovasc Res 2004, 62:447-449.

11. Boison D: Adenosine as a neuromodulator in neurological diseases. Curr Opin Pharmacol 2008, 8:2-7.

12. Fedele DE, Gouder N, Guttinger M, Gabernet L, Scheurer L, Rulicke T, Crestani F, Boison D: Astrogliosis in epilepsy leads to overexpression of adenosine kinase, resulting in seizure aggravation. Brain 2005, 128:2383-2395.

13. Pignataro G, Maysami S, Studer FE, Wilz A, Simon RP, Boison D: Downregulation of hippocampal adenosine kinase after focal ischemia as potential endogenous neuroprotective mechanism. J Cereb Blood Flow Metab 2008, 28:17-23.

14. Fox $I H$, Kelley WN: The role of adenosine and 2'-deoxyadenosine in mammalian cells. Annu Rev Biochem 1978, 47:655-686.

15. Kredich NM, Martin DV Jr: Role of S-adenosylhomocysteine in adenosinemediated toxicity in cultured mouse T lymphoma cells. Cell 1977, 12:931-938.

16. Boison D, Scheurer L, Zumsteg V, Rulicke T, Litynski P, Fowler B, Brandner S, Mohler $\mathrm{H}$ : Neonatal hepatic steatosis by disruption of the adenosine kinase gene. Proc Natl Acad Sci USA 2002, 99:6985-6990.

17. Lawrence de Koning AB, Werstuck GH, Zhou J, Austin RC: Hyperhomocysteinemia and its role in the development of atherosclerosis. Clin Biochem 2003, 36:431-441.

18. Kredich NM, Hershfield MS: S-adenosylhomocysteine toxicity in normal and adenosine kinase-deficient lymphoblasts of human origin. Proc Natl Acad Sci USA 1979, 76:2450-2454.

19. Lloyd HG, Deussen A, Wuppermann H, Schrader J: The transmethylation pathway as a source for adenosine in the isolated guinea-pig heart. Biochem J 1988, 252:489-494.

20. Pereira LA, Schoor S, Goubet F, Dupree P, Moffatt BA: Deficiency of adenosine kinase activity affects the degree of pectin methylesterification in cell walls of Arabidopsis thaliana. Planta 2006, 224:1401-1414.

21. Weretilnyk EA, Alexander KJ, Drebenstedt M, Snider JD, Summers PS, Moffatt BA: Maintaining methylation activities during salt stress. The involvement of adenosine kinase. Plant Physiol 2001, 125:856-865.

22. Sakowicz M, Grden M, Pawelczyk T: Expression level of adenosine kinase in rat tissues. Lack of phosphate effect on the enzyme activity. Acta Biochim Pol 2001, 48:745-754

23. Sahin B, Kansy JW, Nairn AC, Spychala J, Ealick SE, Fienberg AA, Greene RW, Bibb JA: Molecular characterization of recombinant mouse adenosine kinase and evaluation as a target for protein phosphorylation. Eur J Biochem 2004, 271:3547-3555.

24. Singh B, Hao W, Wu Z, Eigl B, Gupta RS: Cloning and characterization of cDNA for adenosine kinase from mammalian (Chinese hamster, mouse, human and rat) species. High frequency mutants of Chinese hamster ovary cells involve structural alterations in the gene. Eur J Biochem 1996, 241:564-571.

25. Juranka $P$, Chan VL: Analysis of adenosine kinase mutants of baby hamster kidney cells using affinity-purified antibody. J Biol Chem 1985, 260:7738-7743.

26. Maj MC, Singh B, Gupta RS: Structure-activity studies on mammalian adenosine kinase. Biochem Biophys Res Commun 2000, 275:386-393.

27. Cui XA, Singh B, Park J, Gupta RS: Subcellular localization of adenosine kinase in mammalian cells: The long isoform of AdK is localized in the nucleus. Biochem Biophys Res Commun 2009, 388:46-50.

28. Gupta RS, Singh B: Quantitative mutagenesis at the adenosine kinase locus in Chinese hamster ovary cells. Development and characteristics of the selection system. Mutat Res 1983, 113:441-454.

29. Gupta RS, Siminovitch L: Genetic and biochemical studies with the adenosine analogs toyocamycin and tubercidin: mutation at the adenosine kinase locus in Chinese hamster cells. Somatic Cell Genet 1978, 4:715-735 
30. Iovannisci DM, Ullman B: Characterization of a mutant Leishmania donovani deficient in adenosine kinase activity. Mol Biochem Parasitol 1984, 12:139-151.

31. Gupta RS: Purine nucleoside analogs. In Drug Resistance in Mammalian Cells. Volume 1. Edited by: Gupta RS. CRC Press, Florida; 1989:89-110.

32. Singh B, Lin A, Wu ZC, Gupta RS: Gene structure for adenosine kinase in Chinese hamster and human: high-frequency mutants of $\mathrm{CHO}$ cells involve deletions of several introns and exons. DNA Cell Biol 2001, 20:53-65.

33. FORD DK, YERGANIAN G: Observations on the chromosomes of Chinese hamster cells in tissue culture. J Natl Cancer Inst 1958, 21:393-425.

34. Mehta KD, Gupta RS: Formycin B-resistant mutants of Chinese hamster ovary cells: novel genetic and biochemical phenotype affecting adenosine kinase. Mol Cell Biol 1983, 3:1468-1477.

35. Daves GD Jr, Cheng CC: The chemistry and biochemistry of Cnucleosides. Prog Med Chem 1976, 13:303-349.

36. Singh B, Gupta RS: Genomic organization and linkage via a bidirectional promoter of the AP-3 (adaptor protein-3) mu3A and AK (adenosine kinase) genes: deletion mutants of $A K$ in Chinese hamster cells extend into the AP-3 mu3A gene. Biochem J 2004, 378:519-528.

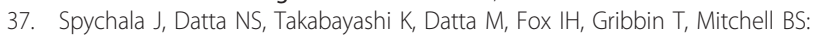
Cloning of human adenosine kinase CDNA: sequence similarity to microbial ribokinases and fructokinases. Proc Natl Acad Sci USA 1996, 93:1232-1237.

38. Rice P, Longden I, Bleasby A: EMBOSS: the European Molecular Biology Open Software Suite. Trends Genet 2000, 16:276-277.

39. Gupta RS, Chan DY, Siminovitch L: Evidence for functional hemizygosity at the Emtr locus in CHO cells through segregation analysis. Cell 1978, 14:1007-1013.

40. Gupta RS: Podophyllotoxin-resistant mutants of Chinese hamster ovary cells: cross-resistance studies with various microtubule inhibitors and podophyllotoxin analogues. Cancer Res 1983, 43:505-512.

41. Gupta RS, Mehta KD: Genetic and biochemical characteristics of three different types of mutants of mammalian cells affected in adenosine kinase. Adv Exp Med Biol 1986, 195(Pt B):595-603.

42. Rabin MS, Gottesman MM: High frequency of mutation to tubercidin resistance in CHO cells. Somatic Cell Genet 1979, 5:571-583.

43. Mathews II, Erion MD, Ealick SE: Structure of human adenosine kinase at 1.5 A resolution. Biochemistry 1998, 37:15607-15620.

44. Schumacher MA, Scott DM, Mathews II, Ealick SE, Roos DS, Ullman B, Brennan RG: Crystal structures of Toxoplasma gondii adenosine kinase reveal a novel catalytic mechanism and prodrug binding. $J \mathrm{Mol} \mathrm{BiO} / 2000$, 298:875-893.

45. Maj MC, Singh B, Gupta RS: Pentavalent ions dependency is a conserved property of adenosine kinase from diverse sources: identification of a novel motif implicated in phosphate and magnesium ion binding and substrate inhibition. Biochemistry 2002, 41:4059-4069.

46. Parducci RE, Cabrera R, Baez M, Guixe V: Evidence for a catalytic Mg2+ ion and effect of phosphate on the activity of Escherichia coli phosphofructokinase-2: regulatory properties of a ribokinase family member. Biochemistry 2006, 45:9291-9299.

47. Lu Q, Inouye M: Adenylate kinase complements nucleoside diphosphate kinase deficiency in nucleotide metabolism. Proc Natl Acad Sci USA 1996, 93:5720-5725.

48. Tokunaga H, Ishibashi M, Arisaka F, Arai S, Kuroki R, Arakawa T, Tokunaga M: Residue 134 determines the dimer-tetramer assembly of nucleoside diphosphate kinase from moderately halophilic bacteria. FEBS Lett 2008, 582:1049-1054.

49. Plunkett W, Gandhi V: Purine and pyrimidine nucleoside analogs. Cancer Chemother Biol Response Modif 2001, 19:21-45.

50. Siminovitch $L$ : On the nature of hereditable variation in cultured somatic cells. Cell 1976, 7:1-11.

doi:10.1186/1471-2091-12-22

Cite this article as: Cui et al:: Molecular Characterization of Chinese Hamster Cells Mutants Affected in Adenosine Kinase and Showing Novel Genetic and Biochemical Characteristics. BMC Biochemistry 2011 $12: 22$.

\section{Submit your next manuscript to BioMed Central and take full advantage of:}

- Convenient online submission

- Thorough peer review

- No space constraints or color figure charges

- Immediate publication on acceptance

- Inclusion in PubMed, CAS, Scopus and Google Scholar

- Research which is freely available for redistribution 